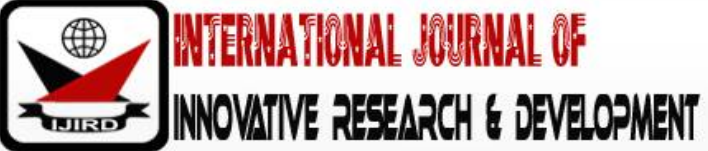

ISSN 2278-0211 (Online)

\section{Sustainable Hospitality in Hotel Designs: An Ideal Process towards Limiting Energy Use in Hotel Facilities}

\author{
Onunwo Chisom N. \\ Student, Department of Architecture, Rivers state University, Nigeria \\ Arc. Tonye D. Pepple \\ Lecturer, Department of Architecture, Rivers state University, Nigeria
}

\begin{abstract}
:
Is no longer news that the cost of energy use in hotel facilities are ever-increasing, and this as a result of not just change in climatic conditions, but the earnest desires to give the customers the best of experience as customers always want something more. Apart from competitions that these various hotel brands face within themselves, yet another smart and intelligent business idea has emerged 'Air bed and Breakfast' founded in 2008, which is positively disrupting the industry and competing with all brands at the same time. This new disruption means most small and medium brands might go out of business as they wouldn't be able to meet up financially! The bigger brands will have to do even more in terms of technology upgrade, human resource, and maintenance and design in general to maximize profits. All these will lead to an increase in energy demand for hotel facilities especially in areas where these competitions are very high like Washington D.C, New York City, Sans-Francisco, Los-Angeles etc. This paper is aimed at outlining the ideal process to be adopted in limiting energy by design for hotel facilities, and identifying technology and management tools, and equipment's to be adopted for best practices.
\end{abstract}

Keywords: ATM-Sustainable design process, hotel design and management, energy-efficient design, cost efficiency, resource conservation, hotel design

\section{Introduction}

The five major concerns of the hospitality industry are provision of constant electricity, water, natural gas, waste management, and flexibility of spaces as the concept of luxury changes with time. Cooling and heating systems consume over 50 per cent of building energy and run largely on fossil fuels at a level of 84 per cent in the European Union for example. Consequently, they are pushing our planet's temperature up to dangerous levels. With energy consumption in the refrigeration, air conditioning and heat pump sectors expected to surge 33 times by 2100, we need to build up renewable energy and energy efficiency to avoid runaway climate change. Ultimately, cooling and heating present huge opportunities to minimize greenhouse gas emissions. With pledges under the Paris Agreement; only taking the world one third of the way towards the cuts needed to limit climate change to $2^{\circ} \mathrm{C}$, we have to seize them. (United nations environmental programme, 2018).

Over time, points related to the idea of sustainability include the 1990s, which brought about the first hospitality specific environmental certification programs; the LEED green building program came into the forefront during the 2000s; the IFC, a member of the World Bank Group, launched its innovative green-building certification system edge program in Vietnam, 2015 to combat climate change. The financial crisis of 2008-2009 prompted hoteliers to reevaluate their cost control measures and reduce utility costs. Contemporarily, the conscious practice of good architecture design in solving energy issues in buildings is seldom to intense installation and use of technological advancements; which in turn increases initial construction cost. It is of eminence that we take into full consideration the principles of architectural design in energy efficiency and sustainability first before the application of technology to manage energy consumptions in building design; as this will not only reduce initial construction cost but overall provide comfort and minimum maintenance throughout the life-time value of the building project. This research paper therefore compliments existing research in the field of sustainable hospitality by reporting the development of an ideal process towards limiting energy use in hotel design by introducing the 'Architecture design, Technology, and Management process' (ATM- Sustainable design process) for hotel designs.

'Architecture and Technology are the perfect fusion for sustainability

But the later should be considered more' (Chisom 0. 2020).

Figure 1.0 below shows the ideal process to be adopted towards limiting energy use in hotel facilities. It illustrates how hotel design moves successfully from the architecture design phase to the application of technology, and to the management tools. It further explains how good architecture design could adopt good management tools/culture with little or no application of technology to reduce initial project cost and still minimize the use of energy consumption. This 
paper will further illustrate and explain each of their benefits with methods of application, the relationship between each of them and the final outcomes will be discussed in this research paper.

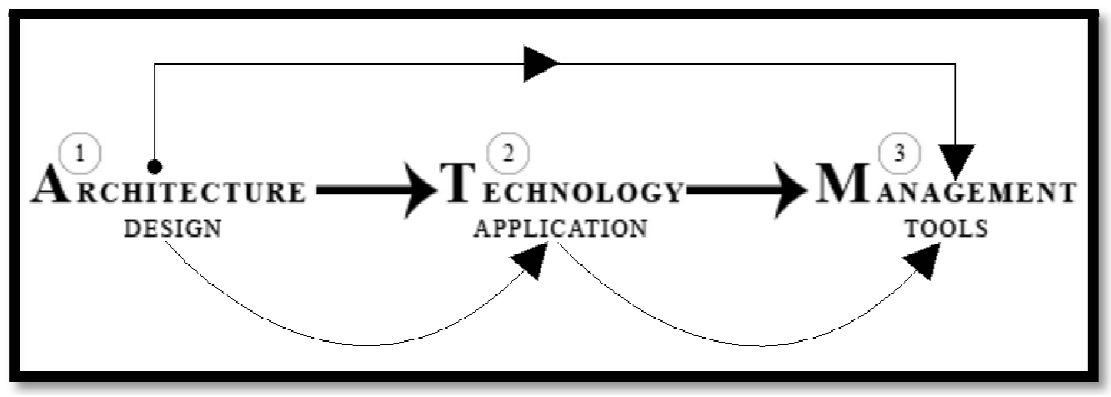

Figure 1: Showing the ATM-Sustainable Design Process

Source: Author

This research paper puts forward strategies and methods to mitigate the environmental impacts of construction activities, thereby facilitating the sustainability of hotel building projects.

\subsection{Statement of Problem}

Generally, hotels require lots of machines and types of equipment for services and their entire operations. The hospitality industry is a leading cause of depletion of natural resources and an increase in carbon footprint. Energy conservation has become a very important focus of the industry; the energy crisis of 1973-74 caused concern about utility costs and energy supply, which prompted hoteliers to focus on energy conservation strategies. Inevitably, to maximize profit in the hotel industry, it has to operate 24 hours every day for a complete 1 year 12 calendar month, with guests expecting certain luxuries, such as restaurants, fitness centers, spas, accommodation, and clubs etc. this poses the problem; how can the industry limit the use of energy but still maintain the level of luxury that guest expects throughout their stay?

\subsection{Aims/Objectives}

- $\quad$ Limit the use of energy by 'Architectural design, technology and management' (ATM)

- $\quad$ Provide ideal guidelines for Limiting energy use in Hotel designs.

- $\quad$ To identify various tools and technological advancements used in the hospitality industry in achieving sustainability and energy efficiency.

\subsection{Methodology}

A qualitative research approach was done to get relevant information's for this topic. Past research on energy efficiency, sustainability and conservation of the hospitality industry was analyzed and categorized as it relates to this research topic.

\section{Literature Review}

As birds to nest, rabbits to holes, so are humans to buildings. Humans love to explore, we get fascinated with beautiful things and our DNA is embedded with creativity; that's why the hotel industry can never go instincts, it can only evolve as the concept of luxury and human exploration changes with time. Technological advancement in response to climatic change has made this evolvement in the hotel industry even more daring than ever before. As interesting as this could be, it also poses a big challenge to the architects and entire construction industry, and the management staff of the hoteliers. The big question is 'will all this changes lead to a better world for all, or will it end into further complications'? the climate will not stop changing, neither will humans stop inventing, but the good news is; an ideal process can be adopted to better harmonize all these to achieve the ultimate goal which is 'energy efficiency and sustainable world for all'. According to a research carried out by national bureau of economic research, USA, February, 2018 for the welfare effects of peer entry in the accommodation market: the case of Airbnb, The concentration of Airbnb bookings in cities and periods of peak demand suggests that in the absence of Airbnb, hotels would be limited in their ability to increase the number of booked rooms - they were already operating at or close to full capacity - but instead would be able to increase prices. Revenues for hotels would increase by $1.54 \%$ if Airbnb did not exist, and profits would likely increase by a larger percent. In fact, it was estimated that the variable profits of hotels could increase by up to $3.69 \%$ across the 10 cities in the samples used. With a good energy efficiency management system in place for hoteliers, they need not to worry anymore about this loss in profits and customers due to growing competitions as this will be covered up even in excess without affecting the cash flow of their business.

\subsection{Energy Use and Conservation}

Hotel owners and guests are expressing their concern for the environment, and both are playing a role in making the hotel industry more sustainable. With the help of government organizations, better technology, and green education, the idea of environmentally friendly hotels is not just an idea; it is becoming the norm. According to an article on Eco Traveler's website, the hotel industry uses 84.7 billion kilowatts of energy, 219 billion gallons of water and creates 1.9 billion pounds of trash per year. 


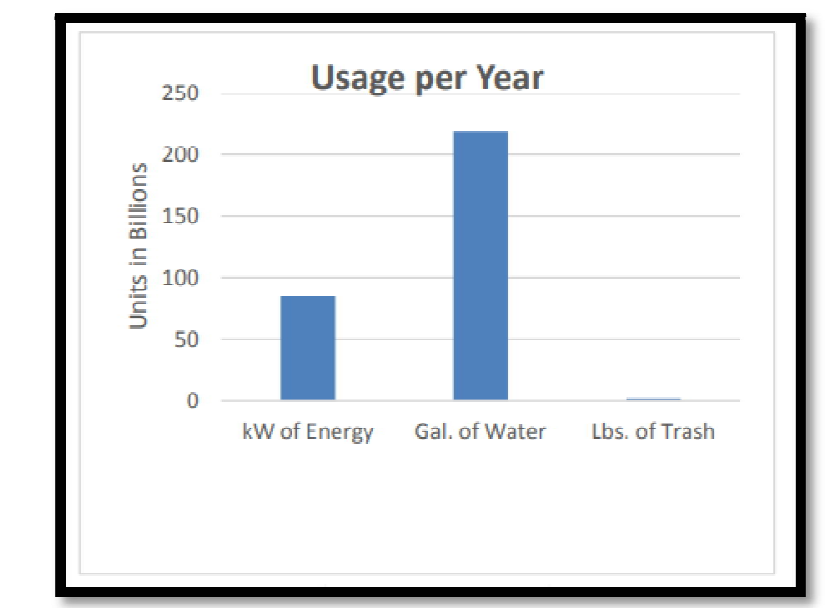

Figure 2: Showing Yearly Consumption of Energy, Water, and Trash Generated Source: (Jenifer, 2013)

An average energy cost of $\$ 2,196$ is spent per guestroom (Energy star, 2008). These staggering numbers are a good representation of why the hotel industry is a perfect candidate for sustainability. The Environmental Protection Agency (EPA) reports that the hotel industry could save $\$ 745$ million annually just by reducing energy use by $10 \%$ (Hetter, 2013). The large consumption of energy and natural resources is part of the reason why a number of organizations were created to address sustainability specifically for the hotel industry. These certifications also added to the marketing strategies used by the big players in the industry while competing for clients, as most lodgers perceive sustainable certified hotels to be more comfortable and healthier regardless of the increase in accommodation cost.

Figure 2.2. Shows Energy consumption comprises $60 \%$ of a hotel's carbon footprint. But it also comprises $60 \%$ of a hotel's utility expenditures. Indeed, energy use eats up 6-10\% of a hotel property's revenues, and is one of the fastest growing operating costs for the hotel industry at large.

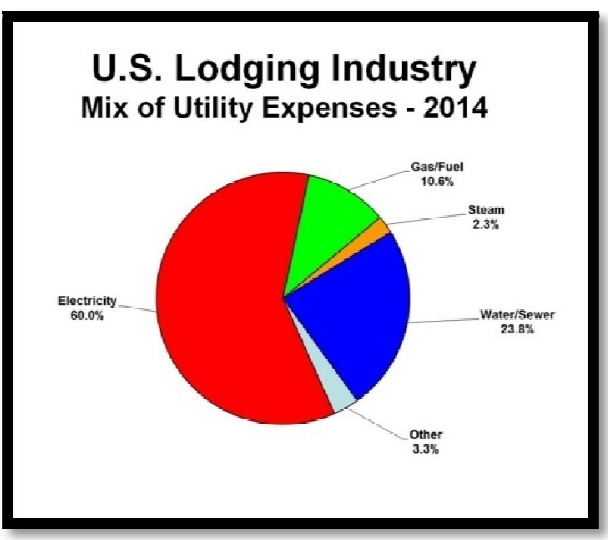

Figure 3: Showing US. Lodging Industry Utitlity Expenses for 2014 Source: PKF Hospitality Research, a CBRE Company, Trends in the Hottel Industry

Reduction of Energy in these segments will have significant cost savings \& will make the hotels eco-friendly. Some of the ways of conserving energy will be further discused in this research paper.

Furthermore, figure 2.4 shows Stages of energy input during the life of a building. As the energy needed for operation decreases, more attention has to be paid to the energy use for the material production, which is the embodied energy. The embodied energy of a building is the total energy required in the creation of a building, including the direct energy used in the construction and assembly process, and the indirect energy that is required to manufacture the materials and components of the building. This indirect energy will include all energy required from the raw material extraction, through processing and manufacture, and will also include all energy used in transport during this process and the relevant portions of the energy embodied in the infrastructure of the factories and machinery of manufacturing, construction and transport. (Akadiri, Ezekiel , \& Paul , 2012). The energy life of a building can therefore be considered to be made up of numerous inputs of operational and embodied energy throughout a building life cycle as shown in Figure 2.4 . 


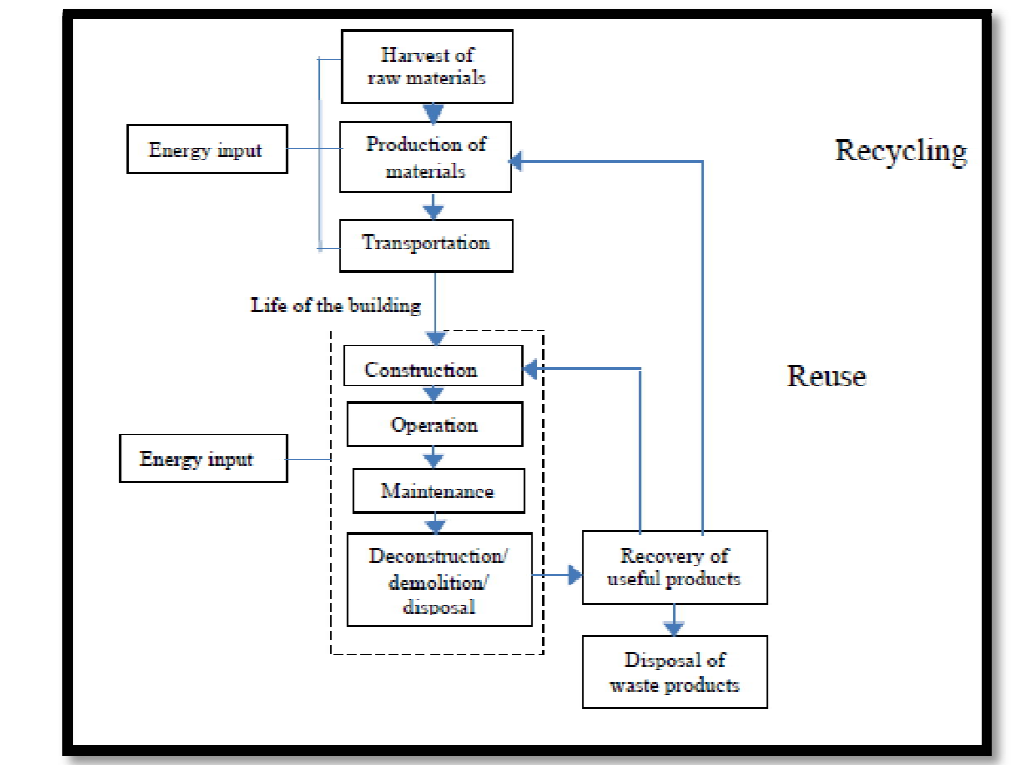

Figure 4: Showing the Stages of Energy Input during the Life of a Building Source: Akadiri, Ezekiel, \& Paul, 2012

Therefore, the main goal of limiting energy use in hotels is to reduce the consumption of fossil fuels, as well as increasing the use of renewable energy sources. This could be best achieved by adopting an acceptable design process which insist on designing with all architectural principles as it applies to the giving project brief, availability of raw material, man-power, and climatic conditions of the giving site location first, which then will give a proper guild on the best of technology to be adopted to increase the energy efficiency of the building throughout its life-cycle without limitation to cost. According to a paper published on the $4^{\text {th }}$ international symposium on Asia pacific architecture, Hawai'i, April, 2001, table 2.1 below further reveals the energy efficiency ratings for different hotels.

\begin{tabular}{|c|c|c|c|c|}
\hline Efficiency Rating & Good & Fair & Poor & Very Poor \\
\hline A) Large hotels (more than 150 rooms) with air conditioning, laundry and indoor swimming pool \\
\hline Electricity (kWh/m2 year) & $<165$ & $165-200$ & $200-250$ & $>250$ \\
\hline $\begin{array}{c}\text { Fuel } \\
\text { (kWh/m2 year) }\end{array}$ & $<200$ & $200-240$ & $240-300$ & $>300$ \\
\hline $\begin{array}{c}\text { Total } \\
\text { (kWh/m2 year) }\end{array}$ & $<365$ & $365-440$ & $440-550$ & $>550$ \\
\hline Hot-water (kWh/m2 year) & $<365$ & $230-280$ & $280-320$ & $>320$ \\
\hline B) Medium-sized hotels (50-150 rooms) without laundry, with heating and air conditioning in some areas \\
\hline Electricity (kWh/m2 year) & $<70$ & $70-90$ & $90-120$ & $>120$ \\
\hline $\begin{array}{c}\text { Fuel } \\
\text { (kWh/m2 year) }\end{array}$ & $<190$ & $190-230$ & $230-260$ & $>260$ \\
\hline $\begin{array}{c}\text { Total } \\
\text { (kWh/m2 year) }\end{array}$ & $<260$ & $260-320$ & $320-380$ & $>380$ \\
\hline Hot-water (kWh/m2 year) & $<160$ & $160-185$ & $185-220$ & $>220$ \\
\hline \multicolumn{2}{c|}{ C) Small hotels (4-50 rooms) without laundry, with heating and air conditioning in some areas } \\
\hline Electricity (kWh/m2 year) & $<60$ & $60-80$ & $80-100$ & $>100$ \\
\hline $\begin{array}{c}\text { Fuel } \\
\text { (kWh/m2 year) }\end{array}$ & $<180$ & $180-210$ & $210-240$ & $>240$ \\
\hline $\begin{array}{l}\text { Total } \\
\text { (kWh/m2 year) }\end{array}$ & $<240$ & $240-290$ & $290-340$ & $>340$ \\
\hline
\end{tabular}

Table 1: Showing Energy Efficiency Rating for Different Types of Hotels Source: Paulina , Angela , \& Ivo, 2001

\subsection{Water Consumption}

According to the environmental protection agency, (EPA), hotels and lodging businesses account for $15 \%$ of total water use in commercial and institution facilities. According to a Duke University study in California, population growth could cause global demand for water to outpace supply by 2050 if current levels of consumption continue. It's everyone's responsibility, including hotel owners, to help combat the dwindling water supply before every state reaches critically low resources. There is a close link between water consumption and energy use, and that often times, reducing the amount of water use, also reduces the amount of energy use. Figure 5shows the possible end use of water in hotel facilities with domestic and restroom activities consuming 30\%, landscaping and laundry service consuming 16\% each and pools having the lowest consumption rate at $1 \%$ respectively. 


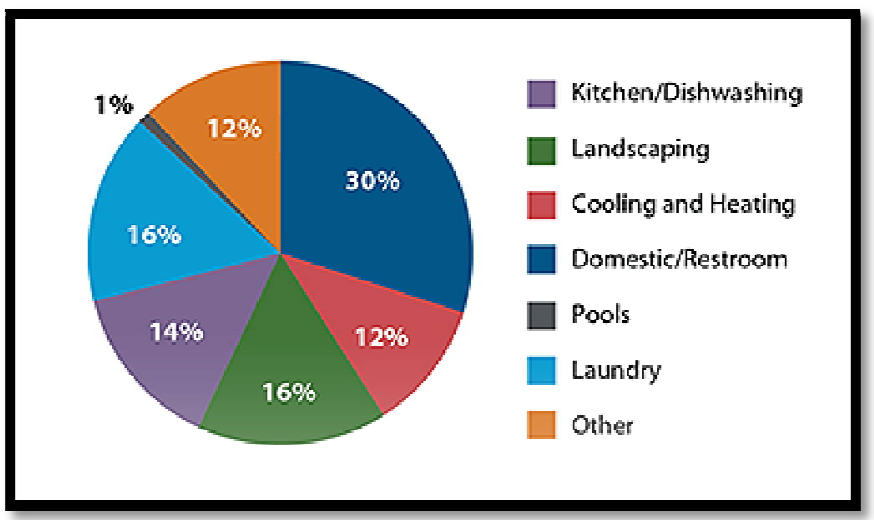

Figure 5: Showing the Percentage of End Use of Water in Hotel Facilities Source: Cerrone, 2016

\subsection{Lighting}

Lighting represents almost a quarter of all electricity consumed in a typical hotel, not including its effect on cooling loads. Lighting retrofits can reduce lighting electricity use by 50 percent or more, depending on the starting point, and cut cooling energy requirements by 10 to 20 percent as well. In guest rooms, CFLs are becoming the standard for table, floor, and reading lamps, and in recessed and vanity lighting in the bathroom. CFLs reduce energy use by two-thirds and yield savings of up to $\$ 20$ per lamp per year. (Attala, 2019). In recent years, it has been discovered that LED lighting stay for longer hours and saves evn more energy.

\section{ATM-Sustainable Design Process}

As shown in figure 1.0 above, this process demonstrates how architecture-technology-management (ATM) can be effectively combined to attain sustainability and energy efficiency in hotel designs. Architecture alone is no longer sufficient to meet with the high level of demand for luxury in contemporary hotel facilities. But ignorance or a complete avoidance of this could lead to a more disastrous outcome. Most designers just pay more attention to aesthetics and the brief with almost total dependence on technology for building operations. The ATM-sustainable design process will better help designers to understand the result of good architecture and how this relates to technology applications and management to achieve the ultimate goal of energy saving and sustainability. A mathematical vein diagram can be used to represent the relationship between these 3 terms and the resulting effect of any two combinations or all using 'A, T, M, a, b, c, and d' as variables respectively as shown in Figure 6below.

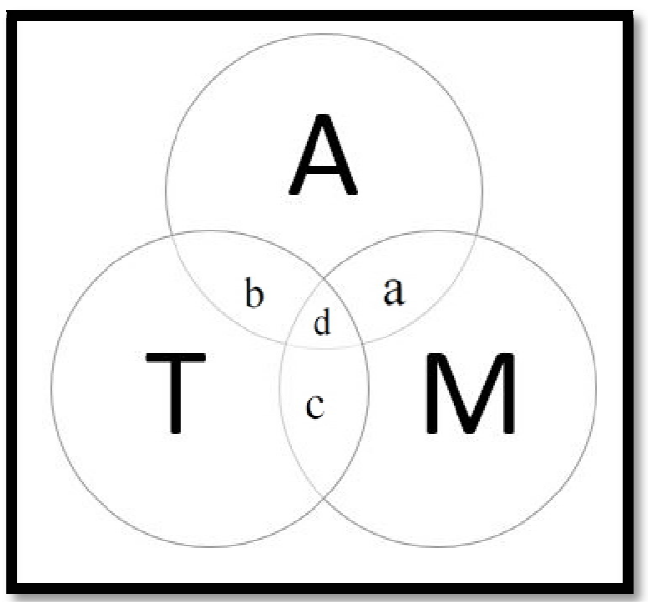

Figure 6: Vein Diagram Showing the Relationship between Architecture-Design, Technology-Application and Management-Tools Respectively Source: Author

Where:

A-Architecture-design: Architecture has always been there since the beginning of time before the invention of any human technology. Some of the Architecture techniques to be adopted in limiting energy use as follows:

- Passive design technique

- $\quad$ Adaptive landscaping (use of flora)

- Use of local/recyclable materials

- Underground/rain water storage

- Building insulation

- Double wall façade/glazing 
T-Technology-Application: As concept of luxury begin to change with time with a rapid increase in climate change, there is therefore a need for application of relevant technology to meet up this demand and while also limiting use of energy consumption. Some of this technology that can be adapted in hotel designs are:

- Solar PV Technology

- Other forms of renewable energy tech. as applicable to the giving project.

- $\quad$ LED lighting

- HVAC energy management Systems

- Grey water Systems

- Smart fixture installations (lights, water taps, showering, water lawns, shading devices, indoor planters, air conditioning etc.)

- $\quad$ Ecopainting practices.

M-Management tools: building assessment and hotel management systems are necessary for overall performance metrics. Some of them have been developed for sustainable accreditation which gives a detailed guild for design and construction practices at every stage of the project. Some are also designed for energy auditing and monitoring and some specifically used as a CRM (customer relationship management) tools. Many but a few to mention are:

- LEED- Leadership in Energy and Environmental Design

- $\quad$ ASHRAE-American Society of Heating, Refrigerating, \& Air-conditioning Engineers

- BREEAM-Building Research Establishment Environmental Assessment Method

- $\quad$ BEES-Building for Environmental and Economic Sustainability

- BIM-Building information management

- EDGE by IFC.

- $\quad$ EMS-Energy management systems

- $\quad$ CRM-Customer relationship management system for hotels (hotelogix etc).

- Other energy auditing management systems. Etc.

a-Architecture design \& Management tools: a careful combination of these two parameters will lead to:

- $\quad$ Reduced overall construction cost

- Low maintenance budget

b-Architecture design \& Technology Application: combination of these two parameters will lead to:

- Time saving

- Flexibility of spaces

- Competitive advantage

- Low consumption control

c-Technology application \& Management tools: the combination of these two parameters will lead to:

- $\quad$ Easy data collection and analysis

- Un-interrupted work flow

- Happy customers

d-Architecture design \& Technology application \& Management tools (ATM): when good architectural practices is been harmonized with technology and agile management systems, limiting the use of energy, and achieving sustainability in hotels becomes a lifestyle. Some of the outcomes are:

- Sustainability

- Energy efficiency

- Durability

- Aesthetics

- Increased assets value

High return on investment (ROI).

\section{Discussion and Recommendations}

According to a report by world economic forum, it is estimated that by 2056, global economic activity will have increased fivefold, global population will have increased by over 50\%, global energy consumption will have increased nearly threefold, and global manufacturing activity will have increased at least threefold. ATM-Sustainable design process is considered as a way for the hospitality industry to move towards achieving sustainable development and limiting energy use taking account Architectural design as it relates to a giving site and project, deployable technological advancements and the overall, the management of these as shown in the mathematical vein diagram in Figure 6above. It is a way of portraying the industry's responsibility alongside key players such as Architects, engineers, manufacturers, inventors, etc. towards protecting the environment.

A decade ago, sustainability in the hospitality sector was a nice-to-have; today it is a business imperative as more and more people not only make sustainable travel choices, and are even willing to pay more for them.

"73\% of global travelers intend to stay at least once in an eco-friendly or green accommodation in the years ahead." Source (sustainable travel report, 2009).

However, to make sustainable and energy saving practices the rule and not the exemptions, it can be accomplished with the involvement of all stakeholders and communication with staff, industry, investors, and cooperation with the quest. Achieving this is not an overnight venture, rather a gradual process that evolves into a daily 
lifestyle. Also, a core team with key staff members who will be primarily involved in overseeing energy conservation plan. For instance, define a timeline to achieve the goal, such as saving

$20 \%$ over the next two years. Simultaneously, create an environment to appreciate people who are meeting the milestones of energy management. (Prakash, 2017).

\subsection{Smart Water Management System}

Water is an essential resource for any hotel operations. Whether it's for food/beverage service, guest room amenities, pools, landscaping, laundry, or sanitation. McGraw-Hill Construction estimates that implementing smart water management systems can reduce water consumption by $15 \%$, energy use by $10 \%$, and overall operating costs by $11 \%$. In other words, by conserving water, hotels also reduce their carbon footprint because they use less energy to manage that water, producing additional operational cost-savings. Of course, there are also the savings in actual water consumption. For instance, a single leaky toilet can cost as much as $\$ 840 /$ year. Add the costs of any additional water damage, and it's remarkable just how quickly that water consumption can lead to unnecessary costs. Some properties have taken smart water management a step further by installing showers systems that filter their own water. The result is that hotels are involving guests in reducing their water consumption, creating an overall more sustainable and rewarding guest experience. (Attala, 2019).

\subsection{A Case of Park Hyatt Melbourne}

It appears that around $30-40 \%$ of the time rooms are unoccupied, providing a potential for a reduction in energy consumption of 20 - 30\%., however, the air conditioning and lights are normally left 'on' by guests. As the growing need to reduce energy consumption increases, The Park Hyatt Melbourne was elected to implement a room management system. The Energy eye room management system has been selected to manage their guest rooms. The control system uses the existing Siemens room controller, monitored by the Siemens BMS to control the utility services of the guest rooms such as air conditioning and lighting. The room controller detects occupants via a door switch and motion detectors. When the room is unoccupied the system resets the room temperature to a pre-defined set point around $26^{\circ} \mathrm{C}$ in summer and $18^{\circ} \mathrm{C}$ in the winter. A large number of different types of LED lamps with different colour and appearances have been trialed to match the aesthetic requirements of the hotel. The LED lamps provide much lower wattage consumption and therefore provide a much more energy efficient lighting option to Park Hyatt Melbourne. The LED lamp increased life expectancy from 2,000 -10,000 hours to 50,000 hours. Table 2 below shows a detailed summary of identified energy saving projects together with their expected savings.

\begin{tabular}{|c|c|c|c|}
\hline Project & Scope & Saving & $\begin{array}{c}\text { Carbon Emission } \\
\text { Savings } \\
\end{array}$ \\
\hline \multirow{2}{*}{$\begin{array}{l}\text { 1. BMS upgrade } \\
\text { with VSD } \\
\text { installation and } \\
\text { energy management } \\
\text { control }\end{array}$} & $\begin{array}{l}\text { Install VSDS on chiller plant } \\
\text { pumps and cooling tower fans }\end{array}$ & \multirow{2}{*}{$\begin{array}{l}\text { Approximately 35\% pump } \\
\text { load, 30\% chiller load, 30\% } \\
\text { cooling tower load, 200kW } \\
\text { saving from demand } \\
\text { management, 2\% saving of } \\
\text { hotel electricity use from } \\
\text { improved housekeeping }\end{array}$} & \multirow[t]{2}{*}{$\begin{array}{c}1,407,386.15 \mathrm{~kg} \mathrm{CO} 2- \\
\mathrm{e} / \mathrm{kWh}\end{array}$} \\
\hline & $\begin{array}{l}\text { Upgrade BMS and Implement } \\
\text { energy management control } \\
\text { functions including: Optimal } \\
\text { chiller control, optimal speed } \\
\text { control for VSDs, demand } \\
\text { management and energy } \\
\text { reporting }\end{array}$ & & \\
\hline $\begin{array}{c}\text { 2. Guest room } \\
\text { management system }\end{array}$ & $\begin{array}{l}\text { Install room management system } \\
\text { for } 240 \text { rooms, including: door } \\
\text { switch, motion detector, FCU } \\
\text { control }\end{array}$ & $\begin{array}{c}\text { Approximately } 21 \% \text { of total } \\
\text { chiller load, } 40 \% \text { in room } \\
\text { FCU fan load and } 40 \% \text { of } \\
\text { heating load of FCUs }\end{array}$ & $\begin{array}{c}\text { 676,565.17 kg CO2- } \\
\text { e/kWh }\end{array}$ \\
\hline $\begin{array}{l}\text { 3. Fluorescent Lamp } \\
\text { replacement - } \\
\text { Option } 2\end{array}$ & $\begin{array}{c}\text { Replace } 500 \text { off } 36 \mathrm{~W} \text { T8 } \\
\text { Fluorescent tubes with } 18 \mathrm{~W} \text { LED } \\
\text { strip lamps }\end{array}$ & $60 \%$ of lamp load & $\begin{array}{c}\text { 195,200 kg CO2- } \\
\text { e/kWh }\end{array}$ \\
\hline $\begin{array}{l}\text { 4. Down Light Lamp } \\
\text { replacement }\end{array}$ & $\begin{array}{l}\text { Replace } 1000 \text { off dichroic down } \\
\text { lights with LED down lights }\end{array}$ & $80 \%$ of lamp load & $\begin{array}{c}\text { 694,044.74 kg CO2- } \\
\mathrm{e} / \mathrm{kWh} \\
\end{array}$ \\
\hline
\end{tabular}

Table 2: Showing Identified Energy Saving Projects at Park Hyatt Melbourne with

Their Expected Savings

Source: Park Hyatt Hotel , 2011

More also, the International Standards Organization (ISO) released ISO 21401: a sustainability management system for accommodation providers. Not only does the new standard address issues related to environmental protection, resource consumption, and waste generation, it also includes matters concerning human rights, local economic development, and the health and safety of employees and guests.

Evaluating the commitment to sustainability by lodging establishments at a global level is finally possible. Ecofriendly hotels that implement ISO 21401 will soon be able to prove that they are indeed sustainable organizations, putting those who pay lip service to green initiatives in serious jeopardy of lost bookings and revenues 


\section{Conclusions}

In every essence, good Architectural practices which includes but not limited to involving a registered and well experience building professionals, is a first mandatory measure that should be taking in pursuit of a much sustainable and energy efficient hospitality industry. The application of technology and management tool as important as they can be to meet up with the ever-trending concepts of luxury and customer certifications, will lead to even more cost and energy consumption if not proper applied with caution as it concerns a giving project.

Every industry undergoes changes and faces new challenges. But climate change and the environment are a set of challenges facing the entirety of humanity. And the only way we will be successful is if we start rethinking the way we live our lives and the way we do business. The hotel industry has been particularly proactive toward this end. From operations to guest experience to how properties are designed and constructed, hotels are implementing more sustainable practices across the board. Many of these measures, moreover, lead to cost-savings that not only cover implementation costs, but reduce overall overhead and increase profitability. In other words, there is a very strong business case for hotels to embrace sustainability and invest now in a cleaner environmental future. The Hospitality industry should therefor 'Make sustainability a commitment, not a marketing strategy'

\section{References}

i. Akadiri, P., Ezekiel , C., \& Paul , O. (2012). Design of A Sustainable Building: A Conceptual Framework for. Buildings, 126-152.

ii. Attala, J. (2019, 7 8). Sustainability Trends in Hotel Management. Retrieved from verdant: https://www.verdant.co/blog/sustainability-trends-in-hotel-management/

iii. Cerrone, B. (2016, 4 3). Hotels Make Room for Water Savings. Retrieved from Hotel Executive: https://www.hotelexecutive.com/business_review/4757/hotels-make-room-for-water-savings

iv. Farronato, C., \& Fradkin, A. (2020, 5 15). THE WELFARE EFFECTS OF PEER ENTRY IN THE ACCOMMODATION MARKET: THE CASE OF AIRBNB. 1050 Massachusetts Avenue, Cambridge, MA 02138: NATIONAL BUREAU OF ECONOMIC RESEARCH. Retrieved from https://www.nber.org/.

v. Jenifer, B. (2013, 11 15). "Sustainable strategies for green hotel design. Retrieved from Eastern Michigan University: http:// commons.emich.edu/thesis/556

vi. MALYAROV, N. (2020, 2 18). Sustainability in hospitality is good business. Retrieved from PreswsReader: https://blog.pressreader.com/sustainability-in-hospitality-is-good-business

vii. Park Hyatt hotel. (2011). Improving Energy Efficiency in a Business Hotel. Retrieved from enman: http://www.enman.com.au/PDF/Case\%20Study\%20-\%20Park\%20Hyatt\%20Melbourne_FINAL.pdf

viii. Paulina , B., Angela , C.-K., \& Ivo, M. (2001). Energy-efficiency and conservation in hotels - towards sustainable tourism. 4th International Symposium on Asia Pacific Architecture (p. 3). Hawai'I: nternational Symposium on Asia Pacific Architecture press.

ix. Prakash, S. (2017, 5 31). How to Improve Your Hotel's Energy Efficiency and Save Costs. Retrieved from Hospitalitynet: https://www.hospitalitynet.org/opinion/4082984.html

$\mathrm{x}$. United nations environmental programme. (2018). UN Environment fights to cut cooling and heating emissions. UNEP. 